\title{
ACESSO À JUSTIÇA: REFLEXÃO TEÓRICA DA ACESSIBILIDADE E AS MODIFICAÇÕES IMPOSTAS PELA LEGISLAÇÃO PROCESSUAL
}

\section{Angelica Denise Klein*}

Resumo: $\mathrm{O}$ artigo discorre sobre o acesso à Justiça, tendo como problemática: é garantido o acesso à Justiça? O tema central é a acessibilidade frente às disposições e vertentes jurisprudenciais que se alteram, de acordo com a matéria, sob o objetivo de permear as bases teóricas, a fim de sopesar as modificações impostas com as alterações legais e, sobretudo a implementação da era digital, sob a justificativa de avaliar a acessibilidade enquanto direito fundamental, norteador dos demais direitos e políticas públicas, utilizando-se como método de pesquisa a revisão bibliográfica, tendo como referencial teórico os autores Mauro Cappelletti e Bryant Garth.

\section{Palavras-chave: Acessibilidade; Acesso à Justiça; Direito fundamental; Jurisdição; Modificações legislativas.}

\section{ACCESS TO JUSTICE: THEORETICAL REFLECTION ON ACCESSIBILITY AND THE CHANGES IMPOSED BY PROCEDURAL LEGISLATION}

\begin{abstract}
The article discusses access to justice, having as a problem: is access to justice guaranteed? The central theme is the accessibility to the dispositions and jurisprudential aspects that change, according to the subject, in order to permeate the theoretical bases, in order to weigh the modifications imposed with the legal changes and, mainly, the implementation of the digital era , under the justification of assessing accessibility as a fundamental right, guiding the other rights and public policies, using as a research method the bibliographic review, having as theoretical reference the authors Mauro Cappelletti and Bryant Garth.
\end{abstract}

Keywords: Accessibility; Access to justice; Fundamental right; Jurisdiction; Legislative changes.

\footnotetext{
${ }^{1}$ Doutoranda em Diversidade Cultural e Inclusão Social pela Universidade Feevale (Novo Hamburgo/RS). Bolsista PROSUP/CAPES I. Mestra em Direito. Advogada. E-mail: angelica.dk@hotmail.com.
}

Revista Brasileira de História do Direito| e-ISSN: 2526-009X| Porto Alegre | v. 4 | n. 2 | 


\section{INTRODUÇÃO}

$\mathrm{O}$ presente artigo $^{2}$ pretende discorrer sobre o acesso à Justiça, tendo como problemática: é garantido o acesso à Justiça? O tema central é a acessibilidade frente às disposições e vertentes jurisprudenciais que se alteram, de acordo com a matéria, sob o objetivo de permear as bases teóricas, a fim de sopesar as modificações impostas com as alterações dos Códigos e, sobretudo com a implementação da era digital, sob a justificativa de avaliar a acessibilidade enquanto direito fundamental, norteador dos demais direitos e políticas públicas, utilizando-se como método de pesquisa a revisão bibliográfica e análises das bases legais e constitucionais do Brasil, tendo como referencial o acesso à Justiça e como marco teórico os autores Mauro Cappelletti e Bryant Garth.

Estruturalmente, o artigo tratará dos conceitos terminológicos e apontará, brevemente, a diferença entre acesso à Justiça e acesso a Jurisdição. Em seguida, a discussão encadeada verificará o acesso à Justiça como direito fundamental, enfrentando os obstáculos perfilhados e as ondas, especialmente, em razão da assistência jurídica. Amparados sob a ótica da virtualização, o exame tangenciará tal norte, evidenciando-se possíveis diferenças no acesso à Justiça de forma virtual e, a par disso, investigar acerca dos direitos e deveres inclusivos e excludentes, sob a perspectiva da forma física e virtual.

\section{ACESSO À JUSTIÇA}

O acesso à Justiça é reconhecido como um direito humano fundamental imprescindível para o ser humano e para o ordenamento jurídico (AGRA, 2009, p.127). Trata-se de um pilar essencial para o exercício da cidadania, cogente para possibilitar a materialização dos demais direitos fundamentais (ANNONI, 2002, p. 35).

$\mathrm{O}$ acesso à Justiça contemporâneo propõe formas, elementos e conceitos incorporados ainda na antiguidade. Para Paulo Cezar Pinheiro Carneiro (1999) o acesso à Justiça retroage às primitivas linhas demarcadas no Código de Hamurabi, no qual se concentram as "primeiras garantias que regulamentavam e impediam a opressão do fraco pelo forte, incentivando-o a procurar a instância judicial quando se sentia oprimido" (CARNEIRO, 1999, p. 4). O acesso à Justiça não se identifica com a mera admissão do processo, uma vez que, para que haja o efetivo acesso à Justiça, torna-se imprescindível a obediência aos preceitos constitucionais (MARINONI, 2015). Para Cândido Rangel Dinamarco (2003, p. 372) o acesso à Justiça pressupõe a "síntese de todos os princípios e garantias do processo, seja a nível constitucional ou

\footnotetext{
${ }^{2}$ Este artigo foi extraído da Dissertação escrita e defendida em março de 2017 pela autora, sob a orientação da Dra. Fabiana Marion Spengler, perante a Banca de Defesa da Universidade de Santa Cruz do Sul (UNISC). A versão integral encontra-se disponível no repositório da UNISC< https://repositorio.unisc.br/ispui/bitstream/11624/1615/1/Angelica\%20Denise\%20Klein.pdf>.
} 
infraconstitucional, seja em sede legislativa ou doutrinária e jurisprudencial". Entretanto, carece considerar o termo "acesso à Justiça" sob o prisma social e filosófico, além do direito. Resgatar conceitos e analisá-los emerge da apreciação dos sentidos das palavras.

Para François Ost (2007) as palavras advindas da literatura podem dimensionar um olhar mais sensível frente à aplicação da lei, empregadas de "forma geral e abstrata", utilizando-se assim, de figuras metafóricas para aguçar o imaginário do interlocutor. 0 imaginário das expressões, dos sentidos e das emoções cogita e impõe uma reflexão frente à terminologia, cominando, ainda que de maneira branda, que o "homem é destinatário" (CICHOCKI NETO, 1998, p. 64), devendo ser garantido (pela sociedade) o acesso à Justiça com uma dupla extensão: estabelecimento de um direito fundamental do homem e uma segurança à realização efetiva dos demais direitos. Dentro deste compasso, atribui que na ambivalência do direito ou da garantia, "o fim último será sempre o de realização da justiça e, por isso, ambos são informados pelo princípio da igualdade" (CICHOCKI NETO, 1998, p. 65).

A Constituição da República Federativa do Brasil não previu de forma literal a terminologia "acesso à Justiça", porquanto o inciso XXXV diz que "a lei não excluirá da apreciação do Poder Judiciário lesão ou ameaça a direito". A construção dialética acerca da proteção jurisdicional do indivíduo frente ao Poder Judiciário, estabelecendo a apreciação das lesões ou ameaça ao direito, compreende ao dimensionamento de garantias fundantes que possibilitam a instrumentalização para o exercício da cidadania plena. Cichocki Neto $(1998$, p. 31) diverge do exercício pleno, sopesando que "a sociedade moderna adquiriu consciência da insuficiência de um estado de direito meramente formal" e, fundamenta que as garantias individuais não proporcionam "instrumentos eficientes e adequados a suas realizações concretas". Na mesma esteira, Miguel Reale (1987, p. 40) propõe o estabelecimento de um "relacionamento equilibrado e dinâmico entre o Poder Público e a sociedade", consagrando-se, assim, o fortalecimento, a partir "das finalidades dos indivíduos, dos grupos naturais e da coletividade em seu conjunto" (REALE, 1987, p. 40).

A preocupação em enfrentar a dificuldade que permeia o acesso à Justiça é remota, nutrindo a necessidade de resolver questões pontuais, como a prestação de assistência jurídica integral aos hipossuficientes de recursos financeiros e, em igual medida, apreciação com os processos morosos. Tais pontos perpassaram pelo tempo, sensibilizando a indigência de enfrentamento pelas políticas públicas. Através de ações e programas voltados à concretização dos direitos individuais e coletivos que o Estado poderá fomentar medidas implementadoras, tendendo à justiça social, sobretudo, considerando que "o ideal de justiça é valorizado por quem procura o Poder Judiciário para resolver um problema e encontra a aplicação do direito com segurança e respeito" (TORRES, 2005, p. 21).

O marco teórico sobre o acesso à Justiça, assinalado por renomados autores da atualidade, aponta a obra de Mauro Cappelletti e Bryant Garth (1988), os quais propuseram o Projeto Florença, que previa um sistema estatal de resolução de controvérsias acessível a todos, direcionando, mais pontualmente, ao âmbito do judiciário e a produção de resultados considerados como "justos", relacionada à efetividade. Os entraves enfrentados no projeto referiram-se ao econômico, ao organizador e ao processual. Igualmente, transcorreram uma análise, sopesando os registros a partir da evolução do conceito teórico de "acesso à Justiça", 
passando pelo significado, pelas soluções práticas, para, enfim, registrar as limitações e os riscos relativos a efetiva implementação estatal. Alertaram, contudo, acerca da extrema dificuldade para identificar a expressão "acesso à Justiça", a qual "serve para determinar duas finalidades básicas do sistema jurídico - o sistema pelo qual as pessoas podem reivindicar seus direitos e/ou resolver seus litígios sob os auspícios do Estado" (CAPPELLETTI; GARTH, 1988, p. 8).

Assim, definiram, de forma substancial, que "o acesso à Justiça pode, portanto, ser encarado como requisito fundamental - o mais básico dos direitos humanos - de um sistema jurídico moderno e igualitário que pretenda garantir, e não apenas proclamar os direitos de todos" (CAPPELLETTI; GARTH, 1988, p. 11). Sob outro viés, numa visão pragmática, Cichocki Neto (1998) pondera as questões de acesso à Justiça a partir de três prismas - político, social e jurídico, destacando que, "sob o prisma político, as questões, relacionadas ao acesso à Justiça, polarizaram-se nos entes que participam do processo e nas relações entre ambos: de um lado, o indivíduo atende dos serviços judiciários; e, de outro, o Estado, prestador da atividade jurisdicional" (CICHOCKI NETO, 1998, p. 17).

A compreensão revisitada de "acesso à Justiça" para Oliveira $(2015$, p. 32) ultrapassa os limites do Judiciário, devendo também ser estruturado pela sociedade civil, pelas empresas, pelos indivíduos e assim, considerar o Judiciário como "órgão presente e atuante, ao lado das demais vias de promoção do justo, não mais como um órgão único, ou primeiro, mas ainda como um órgão último da proteção dos princípios fundamentais".

\subsection{Acesso à Justiça como direito fundamental}

De origem no latim "accêssus" o termo significa ingressar, caminhar, ato de chegar ou se aproximar, denotando uma ação, enfim, um agir. Transportando-se do mundo literário para uma concepção dogmática, a expressão alcança uma análise maior, evoluindo para a possibilidade de dar garantia a uma ação ou mesmo assegurar, a fim de permitir alcançá-la (CONTIJO, 2015).

O acesso à Justiça não é um direito alicerçado exclusivamente na Constituição da República Federativa do Brasil em vigência, porquanto se verifica registros nas constituições brasileiras anteriores, a exemplo da Carta de 1946, momento em que o texto constitucional incluiu o dispositivo prevendo que: "a lei não poderá excluir da apreciação do Poder Judiciário qualquer lesão de direito individual” (BRASIL, 1946). Em igual medida, no mesmo ano, a Declaração Universal dos Direitos dos Homens, no seu artigo 10, dispôs que: "Todo ser humano tem direito, em plena igualdade, a uma justa e pública audiência por parte de um tribunal independente e imparcial" (DUDH, 1948). Desta forma, Tavares (2010, p. 723) pontua que "não há dúvidas que o acesso à Justiça é um direito fundamental presente em diversos textos supralegais".

Neste sentido, Watanabe (1988, p. 135) doutrinou, dentro de um ideário de ordem justa, no mesmo ano da promulgação da Constituição da República Federativa do Brasil (BRASIL, 1988), elencando-se um rol de possibilidades que agregariam aos indivíduos a oportunidade do acesso à Justiça de forma justa, recordando-se que, em tal época, a igualdade entre os sexos começava a dar os primeiros passos, assim como a liberdade e demais direitos fundamentais. De outra ordem, Abrão (2015) fundamenta que o acesso à Justiça assemelha-se, de modo 
simbólico, a uma grande porta, a qual visa assegurar a entrada e a saída, de forma satisfatória e justa, ponderando, contudo, que não é suficiente "existirem inúmeras portas conduzindo à entrada, para acesso ao poder Judiciário, amplas e largas, se há apenas uma única saída, depois de um extenso labirinto" (ABRÃO, 2015, p. 4).

A importância do acesso à Justiça como uma garantia fundamental é delineada por Canotilho e Moreira (2007) como uma "garantia imprescindível da protecção (sic) dos direitos fundamentais", sendo "indispensável para a efetivação de outros direitos fundamentais" (GALDINO, 2007, p. 61-62). Os direitos fundamentais são aqueles que correspondem à manutenção dos pressupostos elementares de uma vida na liberdade e na dignidade humana (GIMENEZ, 2016).

A Constituição da República Federativa do Brasil de 1988 classificou os direitos fundamentais em: direitos individuais (artigo 50-direitos fundamentais do homem como cidadão), direitos à nacionalidade (artigo 12), direitos políticos (artigos 14 ao 17), direitos sociais (artigos 6o e 193), direitos coletivos (artigo 5--direitos fundamentais do homem em uma coletividade), direitos solidários (artigos 3o e 225- direitos fundamentais do gênero humano). (SILVA, 2014) A preocupação temerária permeada por Daniela Olímpio de Oliveira (2015), por outro curso, apresenta-se sob um viés tangenciado ao direito material, como forma de antever que o acesso à Justiça seja assegurado, a fim de prestar a realização na ordem constitucional e infraconstitucional, a "partir de uma relação entre técnica e efetividade dos meios" (OLIVEIRA, 2015, p. 23-24).

O acesso à Justiça é compreendido como um princípio ${ }^{3}$, conforme leciona Ávila (2009, p. 78), porquanto pode ser reconhecido como "normas imediatamente finalísticas, primariamente prospectivas e com pretensão de complementaridade e de parcialidade". Apesar da importância, não se trata de um direito constitucional absoluto, em que pese estar elencado como um direito fundamental, conforme entendimento do Ministro Celso de Mello, no julgamento do Mandado no 23.452 (STF, 2000, p. 89).

A garantia como direito fundamental também perpassa pelos valores, pela ordem do justo ou injusto, e neste sentido Maria Lúcia Amaral (2005) assinala que o "conceito de justo andou sempre associado ao conceito de igual, ou mais especificamente, de tratamento igual de todas as pessoas nas suas relações recíprocas" (AMARAL, 2005, p. 170). E, sob tal norte, Oliveira $(2015$, p. 29) analisa que o acesso à Justiça "ora é tratado pela ótica da acessibilidade ao órgão judicial, ora a publicação é vista pelo seu resultado, sua justiça", de sorte que reflete no direito social como meio de garantir a justiça, com igualdade, dignidade humana e moral.

Dos movimentos alinhavados no Projeto Florença, idealizado por Cappelletti e Garth (1988), tem-se que, para a questão central que move a presente discussão, o quarto movimento incide com maior propriedade, porquanto dirime a necessidade de cautela com a preocupação tendente às prestações do Estado e interesses da sociedade. Dentro deste viés, também se

\footnotetext{
${ }^{3}$ Também denominado princípio da inafastabilidade da jurisdição, princípio da proteção judiciária ou princípio do direito de ação.
} 
considera a fundamentalidade do direito de acesso (CONTIJO, 2015) como um dos pilares (TAVARES, 2010) essencial para garantia alicerçada como direito fundamental, entretanto, não exclusivo, conforme doutrina Morais (2005a, p. 73), equalizando a preocupação entre o Estado e as carências estruturais. Nesta seara, Barbosa (1998, p. 37) leciona que "o problema do acesso à Justiça passa a ser uma questão não de ordem jurídica somente, mas de ordem social e cultural", análise que também é compartilhada por Oliveira (2015, p. 36), a qual acentua que o "momento atual indica que os movimentos renovatórios do acesso à Justiça tendem a tornar-se mais efetivos, afinal o processo está recebendo mais cuidados por parte do Estado". No Brasil a desigualdade social, a pobreza extrema, e a violência (GALLIEZ, 2010) são fatores que provocam perturbação e, por conseguinte, desafios ao Estado e a sociedade. Dentro deste panorama é que a Constituição Federal busca a "redemocratização brasileira" (SANTOS, 2014), a qual perpassa pela necessidade de garantir o acesso à Justiça, assegurando os direitos sociais, políticos, econômicos, culturais, e fomentando as políticas sociais, que acabam sendo deficitárias, ensejando-se, assim, a indigência do acesso ao Poder Judiciário.

Para Boaventura de Souza Santos (2014, p. 13), o protagonismo dos tribunais é uma preocupação temerária decorrente de uma "mudança política", assinalado em razão de dois fatores: a necessidade no cumprimento dos contratos privados, primando por uma estabilidade nas regras do mercado, protegendo-se o consumidor e, por outro viés, devido à "precarização dos direitos económicos (sic) e sociais passa a ser um motivo de procura do Judiciário" (SANTOS, 2014, p. 23). Para exemplificar, registra-se a questão da saúde pública e da assistência farmacêutica, as quais, não obstante constarem, taxativamente, como direito constitucional, encontram entraves na dispensação, de forma administrativa.

As prestações sociais, como é o caso da saúde pública, na sua essência, demandam do critério da urgência, motivo pelo qual encontram no Poder Judiciário resposta "imediata" a sua questão, ou nas palavras de Santos (2014, p. 31) "um serviço equitativo, ágil e transparente". No entanto, tendo em vista que as prestações sociais devem ser fundamentalmente efetivadas pelo sistema da administração pública em detrimento ao sistema judicial. Assim, tal encargo não é uma tarefa fácil, vez que suscita da necessidade de reformulação "do contencioso administrativo" (SANTOS, 2014, p. 25), exigindo-se "maior consolidação da consciência social dos direitos", por parte da sociedade, mas essencialmente, da administração pública. A preocupação na reforma do sistema da administração pública e no protagonismo dos tribunais alicerçou o estudo de Santos (2014) em promover comparações entre o cenário brasileiro e o português e, não obstante, as diferenças econômicas e territoriais, mostraram-se semelhantes quanto à notoriedade da problemática impulsionada pela efetivação das prestações sociais. Tal apreensão não pode ser delineada pela ideia específica de consagração de "um sistema de justiça célere" (SANTOS, 2014, p. 34), mas, especialmente, por um sistema justo, impulsionada por uma revolução democrática da justiça. Para Paulo Galliez (2010, p. 115) a preocupação, no tocante ao que denomina "justiça do asfalto", é alimentada pela violência desencadeada pela exclusão social, encontrando apoio no tráfico de drogas e nos "Chefões", porquanto, há "inegável ruptura com o Estado, permanecendo os moradores alijados de qualquer perspectiva futura, já que esse controle é mantido pelo poder das armas e pelo 
medo". Esta população não consegue acessar a justiça, tampouco os direitos sociais, sendo deficitários da prática da cidadania e do exercício dos direitos.

O direito fundamental de acesso à Justiça pressupõe questões que perpassam, inegavelmente, pelos direitos sociais, políticos, econômicos, individuais e coletivos, influenciando, de forma significativa, na individualidade e na coletividade de cada sujeito, seja ao reivindicar por um direito frente ao Poder Judiciário, seja ao pleitear por um medicamento junto ao sistema de saúde. Dentro deste contexto, é oportuno sublinhar a análise de Amartya Sen (2011) que avalia que "o tema da justiça não diz respeito apenas à tentativa de alcançar- ou sonhar com a realização de- uma sociedade perfeitamente justa ou arranjos sociais justos, mas à prevenção de injustiças manifestadamente graves" (SEN, 2011, p. 51).

A busca por um acesso à Justiça que atenda aos anseios da sociedade demanda uma mudança no formato do cenário, sinalizando-se pela necessidade de acolher a possibilidade de uma redemocratização indicada por Santos (2014) como forma de ultrapassar as barreiras de acesso (CAPPELLETTI; GARTH, 1988), as quais perpassariam também pela prestação de assistência jurídica integral, além de outros elementos, que possibilitassem o pleno exercício dos direitos.

\subsubsection{Assistência jurídica integral}

Ao concentrar esforços para possibilitar uma assistência jurídica integral, o movimento em busca do amplo acesso à Justiça defendido por Cappelletti e Garth (1988) idealizado num modelo que permitisse a assistência judiciária pelo sistema de advogados remunerados com exclusividade pelos cofres públicos. Para tanto, na época, o modelo foi adotado na Áustria, Inglaterra, Holanda, França e na Alemanha Ocidental, denominando-se sistema judicare, que consistia em "um sistema através do qual a assistência judiciária é estabelecida como um direito para todas as pessoas que se enquadrem nos termos da lei, Os advogados particulares, então, são pagos pelo Estado" (CAPPELLETTI; GARTH, 1988, p. 35). Visando soluções práticas para enfrentar os entraves do acesso à Justiça, Cappelletti e Garth (1988) instituíram os movimentos denominados como "ondas", com a intenção de estabelecer métodos. Tais "ondas" seriam, segundo defende Vladimir de Carvalho Luz (2008, p. 43) classificadas como "tendências teóricas e formas concretas de fomento do acesso à Justiça". Muito embora o projeto idealizado não restou concebido pelo Brasil, os movimentos ou ondas representam um marco importante para a discussão teórica do acesso à Justiça, alicerçando paradigmas frente à problemática de rediscussão da forma de prestação da assistência judiciária aos necessitados, expressão conduzida pela Constituição Federal de 1988.

A primeira onda ou movimento, portanto, é a assistência judiciária aos hipossuficientes, como forma de envolver os indivíduos com escassas condições financeiras e sociais a conhecerem seus direitos, não se intimidando com os valores relativos aos custos dos processos e das taxas judiciárias (CAPPELLETTI; GARTH, 1988). Verificando-se a necessidade de dispensar o atendimento integral às pessoas que, comprovadamente, apresentarem insuficiência financeira, sobreveio o inciso LXXIV, no artigo 5o da Constituição Federal da República Federativa do Brasil (BRASIL, 1988) elencado como garantia fundamental. No entanto, tal segurança pressupõe apenas a problemática financeira, exigindo-se, para tanto, a comprovação. Tal exigência, contudo, poderá inibir o efetivo acesso à Justiça daqueles indivíduos que, por questões adversas, não conseguem demonstrar a insuficiência de recursos, 
em razão de conhecimento considerado precário, intensificando-se quando conjugado aos fatores políticos e sociais.

A segunda onda importa na representação dos interesses difusos, os quais são conceituados por Cappelletti e Garth (1988, p. 26) como "interesses fragmentados ou coletivos, tais como o direito ao ambiente saudável, ou à proteção do consumidor". Assim, os direitos difusos não apresentariam, por certo, apenas um titular de direito a ser identificado, porquanto seriam reivindicados para a coletividade, perquirindo-se a mesma finalidade. A problemática evidenciada pelos autores é a desconfiança na "máquina governamental para proteger os interesses públicos e dos grupos" (CAPPELLETTI; GARTH, 1988, p. 28), ao passo que a terceira onda pressuposta pelos autores traduz-se, incisivamente, na concepção mais ampla do acesso à Justiça, despendendo medidas efetivas para alcançar os direitos a "qualquer indivíduo" (CAPPELLETTI; GARTH, 1988, p. 29 e p. 67-68).

Almejar uma prestação jurisdicional justa, equânime e igualitária enfrenta uma problemática retratada por Santos (1995, p. 167) como "desigualdade sócio-econômica", que restringe a justiça social. Traduz-se numa justiça considerada de alto custo para os cidadãos em geral, "mas é proporcionalmente mais cara para os cidadãos economicamente mais débeis" (SANTOS, 1995, p. 168) que, além do fator financeiro, também são prejudicados frente aos empecilhos sociais e culturais.

A Lei no 1.060, de 05 de fevereiro de 1950 (BRASIL, 1950) estabelecia normas para a concessão judiciária aos necessitados, restando parcialmente revogada pela Lei no 13.105, de 16 de março de 2015 (BRASIL, 2015), que alterou a análise de apreciação dos pedidos. Dentre as implementações constitucionais, tem-se a possibilidade da benesse nos processos envolvendo a cooperação jurídica internacional (artigo 26, CPC/2015), como é o caso dos refugiados, que gozarão de assistência judiciária gratuita durante o período de análise do pedido de refúgio, desde que estejam em situação regular.

O artigo 98 da aludida Lei, ordinariamente denominada como Código de Processo Civil, previu que é assegurada a Gratuidade da Justiça "a pessoa natural ou jurídica, brasileira ou estrangeira, com insuficiência de recursos para pagar as custas, as despesas processuais e os honorários advocatícios tem direito à gratuidade da justiça, na forma da lei". A outra alteração em relação à legislação anterior refere-se ao pedido de gratuidade que, no momento, pode ser formulado na própria petição, com presunção de veracidade, conquanto anteriormente exigiase uma declaração de hipossuficiência (artigo 99, CPC/2015).

O Tribunal de Justiça do Estado do Rio Grande do Sul apregoa que o limite para concessão de gratuidade da justiça é a comprovação dos rendimentos "abaixo do equivalente a cinco salários mínimos"4. No âmbito do Tribunal Regional Federal da 4a Região, por outro lado, até o advento da Lei no 13.105/2015 havia duas vertentes jurisprudenciais, uma adotando o limite de até dez salários mínimos nacionais ${ }^{5}$, enquanto que a outra previa a inexistência de limite para a

\footnotetext{
${ }^{4}$ Agravo de Instrumento No 70069786630, Nona Câmara Cível, Tribunal de Justiça do RS, Relator: Carlos Eduardo Richinitti, Julgado em 09/06/2016.

${ }^{5}$ TRF4, AG 0007778-52.2012.404.0000, Sexta Turma, Relator Néfi Cordeiro, D.E. 26/10/2012.
} 

IMPOSTAS PELA LEGISLAÇÃO PROCESSUAL

concessão do benefício ${ }^{6}$. Atualmente, considerando que a redação do atual Código de Processo Civil (CPC, 2015) assinala uma presunção legal de pobreza, o Tribunal Regional Federal da 4으 Região (TRF4) prevê o descabimento de fixação de limites, sendo suficiente a declaração, para presumir a impossibilidade de custear a despesa do processo, sendo desnecessária, por seu turno, a comprovação de miserabilidade ${ }^{7}$. Assim, considerando que não há uniformidade na adoção de concessão da gratuidade, uma vez que o Tribunal de Justiça do Estado do Rio Grande do Sul determina a adoção de um limite (até cinco salários mínimos nacionais), enquanto que o TRF4 entende que é desnecessária a fixação de limitação quanto à impossibilidade de recursos financeiros, o usuário se sujeitará aos entendimentos jurisprudenciais quando necessitar acessar a justiça para postular a prestação jurisdicional. A prestação de assistência jurídica de "alta qualidade acessível a todos" era o ponto importante para Cappelletti e Garth (1988, p. 143), incidindo-se não apenas na atuação dos advogados, mas também no trabalho em "tornar as pessoas mais ativamente participantes das decisões básicas, tanto governamentais quanto particularmente, que afetam suas vidas". Não obstante a alteração no Código de Processo Civil, o papel do advogado (privado ou público) mostra-se elementar para a prestação jurídica. Cichocki Neto (1998, p. 116) demonstrava um olhar de descrença sobre o atendimento jurídico, quiçá, pela época em que doutrinou momento em que a defensoria pública caminhava a passos lentos e o judiciário ainda estava sob a égide do Código de Processo Civil de 1973.

A Defensoria Pública da União, do Distrito Federal e dos Territórios restou organizada a partir da publicação da Lei Complementar no 80, de 12 de janeiro de 1994 (BRASIL, 1994). Na redação original tratava-se de uma instituição essencial à função jurisdicional do Estado, incumbindoIhe a prestação da assistência jurídica, judicial e extrajudicial integral e gratuita aos necessitados. No entanto, a Lei complementar no 132/2009 alterou a disposição, passando a ser reconhecida como um instrumento democrático (BRASIL, 2009). Analisando-se a possibilidade de atendimento jurídico através da Defensoria Pública, buscou-se informações junto ao Instituto de Pesquisa Econômica Aplicada (IPEA), o qual realizou conjuntamente a Associação Nacional de Defensores Públicos (ANDEP) uma pesquisa que apurou um déficit de defensores públicos em aproximadamente setenta e duas comarcas brasileiras: "a Defensoria Pública só está presente em 754 das 2.680 comarcas distribuídas em todo o país" (IPEA, 2013). Assim, o IPEA considerou que havia um déficit considerável de defensores públicos, tendo Estados que contavam com advogados nomeados. A Emenda Constitucional no 80, de 04 de junho de 2014 (BRASIL, 2014) determinou o prazo de oito anos para adequação da demanda proporcional à respectiva população. Por sua vez, a Defensoria Pública da União editou a Resolução no 85, de 11 de fevereiro de 2014 (DPU, 2014), fixando parâmetro objetivo para presunção e comprovação da necessidade das pessoas naturais e jurídicas. Para tanto, o artigo 1 ㅇau que, "presume-se economicamente necessitada a pessoa natural que integre núcleo familiar, cuja renda mensal bruta não ultrapasse o valor total de 03 (três) salários mínimos". A

\footnotetext{
${ }^{6}$ TRF4, Incidente de Uniformização de Jurisprudência na Apelação Cível no 5008804-40.2012.404.7100, Corte Especial, Relator Desembargador Federal Carlos Eduardo Thompson Flores Lenz, Relator para Acórdão Desembargador Néfi Cordeiro, por maioria, julgado em 22.11.2012.

${ }^{7}$ (TRF4, Agravo de Instrumento $n^{\circ}$ 5023253-21.2016.4.04.0000/PR, Terceira Turma, Relator Desembargador Federal Fernando Quadros da Silva. D.E.03/06/2016.).
} 
limitação do critério econômico agregada ao número mínimo de defensores públicos pode gerar a necessidade de contratação de defensor privado, o qual, segundo a redação do artigo 133, "é indispensável à administração da justiça" (BRASIL, 1988).

Os mecanismos incentivando o exercício do papel social do advogado-público ou privado-não podem estar alicerçados ao estigma de "cuidado com os pobres", porquanto a prestação do atendimento deve primar pela assistência jurídica adequada. Neste sentido, destaca-se Santos (2014) ao sinalizar que "a assistência jurídica prestada é judicial e extrajudicial, integral e gratuita", e, dentro deste compasso, sublinha que se faz necessário "outra cultura de consulta jurídica e de assistência ao patrocínio judiciário" (SANTOS, 2014, p. 53), imputando à Defensoria Pública um papel fundamental de ativismo jurídico. Neste contexto, Galliez (2010) avalia a necessidade de uma reestruturação na Defensoria Pública, propondo uma infraestrutura capaz de prestar atendimento adequado que não se restrinjam ao tratamento dos litígios. Apresenta-se, portanto, as possibilidades de composição consensuada e autônoma dos conflitos, através da mediação e da conciliação, como sublinha Spengler (2016), além do movimento da desjudicialização (OLIVEIRA, 2015) como meios complementares de resolução de controvérsias.

\subsection{Acesso à Justiça de forma virtual}

Considerar a tecnologia, em termos globais e informacionais, alvitrando-se das sociedades e, sobretudo dos sujeitos, demandou para Manuel Castells (2005, p. 40) examinar a instituição do "sistema de comunicação que fala cada vez mais uma língua universal digital, promovendo a integração global da produção e distribuição de palavras, sons e imagens de nossa cultura", buscando-se uma identidade. A tecnologia inseriu a televisão, a radiodifusão, o computador e a Internet, além dos termos como infoexcluídos, que se referem à desigualdade no acesso à Internet, em conectar e desconectar. Os termos acesso à Justiça e comunicação de acesso à distância são diversos, pois um é assegurado constitucionalmente, enquanto que o outro advém da interpretação normativa, de acordo com a Lei no 11.419 (BRASIL, 2006). Duas garantias que quando empregadas conjuntamente transformam-se em um mecanismo que traz em seu cenário um equipamento considerado como primordial, para possibilitar o acesso: o computador. Segundo a concepção de Pierre Lévy (1996) este permite acessar ou mesmo alcançar o mundo em centésimos/milésimos de segundos, como defende Castells (2005). A busca pela identidade junto às redes interativas de computadores, ao mesmo tempo em que adapta a vida, também acaba sendo moldada pelos canais de comunicações, carecendo-se, no entanto, cautela entre o conectar e o desconectar indivíduos, grupos ou regiões, a fim de afastar a "oposição bipolar entre a Rede e o Ser", fator que pode estabelecer uma espécie de "esquizofrenia estrutural entre a função e o significado, os padrões de comunicação social ficam sob tensão crescente" (CASTELLS, 2005, p. 40-41). Discorrendo-se em sua obra, numa década em que a Internet ainda era conduzida pela minoria dos sujeitos, Lévy (1996, p. 5) ponderou a imperatividade de sublinhar a expressão "virtual" que, em certa medida, é empregada de forma equivocada.

O cenário do acesso à Justiça se transformou com a utilização do computador e das redes digitais, alterando-se o modo de ingressar, de se comunicar, de se manifestar e de sentenciar. 
Acredita-se que a forma de acesso à Justiça, como elemento preponderante, modificou exponencialmente a maneira de acessar de físico para eletrônico.

As inovações tecnológicas foram incorporadas pelas indústrias, pelo comércio e pela educação gerando impactos positivos, mas, ao mesmo tempo, motivando espaços para promoção de discussões. A possibilidade de conectar, através de um sistema de informação, ou nas palavras de José Carlos de Araújo Almeida Filho (2015, p. 43), um movimento tendente a promover uma ampla sociedade da informação tecnológica, ultrapassando as "barreiras geofísicas e comunicações velozes, quase que imediatas. Um território sem ideia de poder central, mas com hierarquia sem sua estrutura que, estranhamente, foi aceita pelo mundo inteiro" e complementa "estamos vivenciando uma nova fase que nos perturba profundamente: a ideia de uma sociedade, devidamente hierarquizada, mas sem as características de nação e soberania. Temos povo, se admitirmos pessoas unidas em torno de algo em comum, mas não temos nação e soberania" (ALMEIDA FILHO, 2015, p. 43).

A tecnologia avança no espaço, de forma incomensurável, ligando e interligando as pessoas através de uma "simples tecla no computador" (ALMEIDA, FILHO, 2015, p. 50) ou mesmo, por meio de outros equipamentos de informática. Para Lévy (1996) a rede é o espaço desterritorializado, não se permitindo, tão-somente, o que o autor define como "informática contemporânea-soft e hardware", mas sim, a desconstrução do computador cedendo lugar a um ambiente de "comunicação navegável e transparente centrado nos fluxos de informação" (LÉVY, 1996, p. 27).

A inclusão digital no Brasil é um tema relativamente recente, porquanto, somente em 2009, instituiu-se o Programa Nacional de Apoio à Inclusão Digital nas Comunidades, por meio do Decreto no 6.991, de 27 de outubro de 2009 (BRASIL, 2009), no âmbito da política de inclusão digital do Governo Federal, cujo objetivo primordial consistia no desenvolvimento de ações possibilitando a implantação e a manutenção de telecentros públicos e comunitários no território nacional, sem prejuízo da continuidade e implementação de outros programas da mesma natureza. Em 2010, editou-se o Programa Nacional de Banda Larga (PNBL), por meio do Decreto $n$ o 7.175, de 12 de maio de 2010 (BRASIL, 2010), tendo como finalidade fomentar e difundir o uso e o fornecimento de bens e serviços de tecnologias de informação e comunicação. Entretanto, apesar dos programas estabelecidos, o Banco Mundial informou, por meio do Relatório sobre o Desenvolvimento Mundial 2016, que no Brasil 98 (noventa e oito) milhões de pessoas ainda não têm acesso à Internet e, em razão disso, o país encontra-se na quinta colocação, atrás da China, dos Estados Unidos, da Índia e do Japão. (DIVIDENDOS DIGITAIS, 2016). Assim, como forma de reduzir o número, o Banco Mundial sugeriu a criação de ambiente certo para a tecnologia, com regulamentações, capacitações dos trabalhos, investimentos na estrutura básica e redução dos custos, a fim de facilitar a concorrência das plataformas digitais. Recentemente, o Ministério das Comunicações adequou o programa, sob o objetivo de "universalização do acesso à Internet e o aumento da velocidade média da larga fixa no país" (MINISTÉRIO DAS COMUNICAÇÕES, 2016).

Visando à inclusão dos marginalizados digitalmente, tem-se o projeto dispondo acerca da Política Nacional de Inclusão Digital, a qual será incorporada a Política Nacional de Apoio à Inclusão Digital nas Comunidades, tendo como norte a promoção da cidadania. Entretanto, não 
obstante as iniciativas do Estado na instituição de Políticas Públicas, o cenário denota maior preocupação quando se estreita a relação com o acesso à Justiça (ABRÃO, 2015, p. 4). Na compreensão de Almeida Filho (2015, p. 46) o "Judiciário ainda não se encontra completamente preparado com os meios disponíveis para conviver com o subsídio revolucionário", fundamentando-se, portanto, a ideia da tecnodemocracia proposta por Lévy (1996), de forma a assegurar a importância de interligar a inclusão da tecnologia com a esfera política (ALMEIDA FILHO, 2015, p. 47).

O acesso à Justiça de forma virtual contempla uma preocupação considerada por Almeida Filho (2015) como necessária, uma vez que a informática e o direito são dicotômicos. Ao se analisar o acesso de forma virtual, inegavelmente adentra-se numa área do Direito Eletrônico, o qual, apesar de recente na seara brasileira, carece de um olhar mais atento, porquanto a virtualização e os processos eletrônicos estarão em rede. Contudo, ainda demarcada pela "resistência quanto à implantação de meios eletrônicos, seja no sistema judicial, seja no próprio ordenamento controlador da sociedade" (ALMEIDA FILHO, 2015, p. 61), sobretudo, com a temerária segurança das informações que tende a se alterar, por parte da mudança quanto à mentalidade do "papel", o qual "passa a não mais existir" (ABRÃO, 2015).

A garantia ao acesso, de forma virtual, coaduna-se com a pretensão alinhavada por Cappelletti e Garth (1988, p. 156) ao frisar pelo movimento de simplificação do Direito. Contudo, ponderase que simplificação não é sinônimo de exclusão de direitos, "paliativo isolado de todos os aspectos consolidados" (ABRÃO, 2015, p. 5), uma vez que se faz necessário incentivo para integração de novos sistemas, a fim de garantir o acesso à Justiça de forma virtual, mecanismo que demanda a inclusão digital de todos, especialmente, dos excluídos marginalmente, também designados como analfabetos digitais ou infoexcluídos.

\subsubsection{Direito ou dever: o acesso à Justiça de forma virtual inclui ou exclui os indivíduos?}

A garantia do acesso à Justiça de forma virtual cominou analisar a exclusão com inclusão, partindo de unidades diversificadas com o objetivo de alcançar a justiça. Para tanto, Almeida Filho (2015) idealizou o sistema " $X$ " da desigualdade, que visualmente pode ser examinada:

\footnotetext{
Necessidade de Acesso à Justiça

Exclusão digital

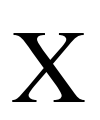

Acesso à .Iustica

Inclusão digital

Fonte: ALMEIDA FILHO, 2015, p. 96.

Assim, Alnneida Filho (2015) assinala que deve-se atentar para os excluídos digitalmente que além de não terem acesso à informática, também estão desprovidos de instrumento capaz de efetivar a cidadania. Portanto, a atenção deve partir das regiões mais deficitárias e que apresentam o número mais acentuado de marginalizados digitalmente. Para o sociólogo Sérgio Amadeu da Silveira (2001), a inclusão digital transpõe ao manuseio do computador, promovendo-se a interação através das redes digitais como forma de reduzir as desigualdades, potencializada em razão do "analfabetismo digital, da pobreza e da lentidão comunicativa, do isolamento e do impedimento do exercício da inteligência coletiva" (SILVEIRA, 2001, p. 18). Com a finalidade de ensejar a promoção da inclusão dos excluídos digitalmente, possibilitandose o acesso à Justiça, o computador poderia ser um “operador de potencialização da
} 
informação", permitindo que a tela (monitor) fosse uma "pequena janela a partir do qual o leitor explora uma reserva potencial" (LÉVY, 1996, p. 22). Não bastaria o computador, uma vez que este deve ser integrado à rede mundial conectando-os com a era digital (SILVEIRA, 2001), ensejando-se as condições básicas para possibilitar a capacitação e o conhecimento do "analfabeto digital" (TAVARES, 2008a, s.p. ${ }^{8}$ ). Partindo-se do contexto normativo, o acesso à Justiça de forma virtual, perante o Poder Judiciário, tornou-se uma obrigação impositiva, porquanto desde o advento da Emenda no 45/2004 (BRASIL, 2004) há um intenso movimento para implementar o processo eletrônico nas justiças estaduais, federais e especializadas. Ao se examinar os direitos e deveres dos indivíduos, cabe acentuar os direitos e os deveres do Estado, ao qual restou "delegada a função de dizer o Direito" (SPENGLER, 2010, p. 39). De um lado, a legislação coaduna-se com a ideia de que a forma virtual é inclusiva, não obstante a necessidade primária de envolver mecanismos que possibilitem a inclusão digital, iniciando-se pelos treinamentos dos sujeitos que se encontram na sociedade além dos atores processuais; de outra banda, na doutrina há duas correntes- uma inclusiva comandada por Carlos Henrique Abrão (2015) e Edilberto Barbosa Clementino (2012) e, outra exclusiva, norteada por José Carlos de Araújo Almeida Filho (2015), que aduz "Exclusão com inclusão, ainda que em polos e modos distintos, mas com um mesmo objetivo: ACESSO À JUSTIÇA!" (ALMEIDA FILHO, 2015, p. 98).

Seguindo a análise de Almeida Filho (2015), a exclusão digital acomete aos "necessitados", terminologia adotada pela Constituição da República Federativa do Brasil (BRASIL, 1988) ou, igualmente, os "vulneráveis". Dentro deste cenário, encontram-se as crianças, os hipossuficientes, os presos que estão no sistema prisional ou em monitoramento eletrônico, os idosos e demais sujeitos que não acessam o sistema digital e, por derradeiro, estão marginalizados da forma virtual. Ponderando-se a importância do computador, assim como dos demais aparelhos em rede, a exemplo da televisão e radiodifusão, Castells (2005, p. 441) ressaltou preocupação relativa à acentuada desigualdade social.

Neste sentido, verifica-se que entre o direito de acessar a justiça de forma virtual e o dever do Estado de disponibilizar a inclusão digital, tem-se a necessidade de ampliação do acesso à informática, à era digital, aos mecanismos virtuais, em especial nas regiões mais deficitárias, como forma de incluir digitalmente. Em segundo momento, despender treinamento aos usuários, pois "o conhecimento e a informação não são "imateriais", mas desterritorializados; longe de estarem exclusivamente presos a um suporte privilegiado, eles podem viajar" (LÉVY, 1996, p. 35). Adentrando-se no sistema de informação, transforma-se o analfabeto digital e funcional em "pessoas digitalmente incluídas" (MATTOS; CHAGAS, 2008, p. 72), análise que incide na promoção de políticas públicas inclusivas.

\section{CONCLUSÕES}

O presente artigo discorreu sobre o acesso à Justiça, tendo como problema norteador a pergunta se é garantido o acesso à Justiça? Acredita-se que a resposta é ambígua, dependendo

\footnotetext{
${ }^{8}$ s.p. $=$ sem página.
} 
do viés em que se posiciona o interlocutor. Considerando as divergências nas vertentes jurisprudências acerca do limite (ou a ausência de) para requerer o benefício de Gratuidade da Justiça, o cidadão jurisdicionado receberá variadas formas de tratamento. As modificações trazidas pelo Código de Processo Civil no que tange a era digital foram significativas para o novo delinear do acesso à Justiça, o qual apesar da extrema discussão teórica ainda carece de reflexão.

Dentre as conclusões obtidas a partir deste estudo, verificou-se que o acesso à Justiça é uma garantia fundamental prevista na Constituição da República Federativa do Brasil e, sob tal norte, deve-se assegurar que todos tenham direito de forma qualificada. Contudo, em relação ao acesso a Jurisdição, verificou-se que, outrora e, também, na atualidade, os entraves obstaculizando o ingresso acabam por impossibilitá-lo. Quando ultrapassa a primeira "porta", adentrando no Judiciário, não alcança a saída, a qual acaba sendo dificultada em razão da prestação jurisdicional tardia ou retardatária. $\mathrm{O}$ acesso virtual, além dos obstáculos pontuados, enfrenta, ainda, as deficiências estruturais relativas à Internet e ao computador. O prejuízo decorrente da ausência de ingresso devido à inexistência da Internet nas zonas rurais e fronteiristas impossibilita o acesso ao processo de forma virtual.

\section{REFERÊNCIAS}

ABRAMO, Claudio W. Tempos de espera no Supremo Tribunal Federal. Revista Direito GV, v. 6, n. 2, p. 423-442, 2010. Disponível em:< http://www.scielo.br/scielo.php?script=sci_nlinks\&ref=000119\&pid=S0034$7612201300020000500001 \& \operatorname{lng}=\mathrm{en}>$. Acesso em: 14 nov. 2016.

ABRÃO, Carlos Henrique. Processo eletrônico, processo digital, de acordo com o novo CPC. 4. ed. revista, atualizada e ampliada. Sao Paulo: Atlas, 2015.

ALMEIDA FILHO, José Carlos de. Processo eletrônico e teoria geral do processo eletrônico. A informatização judicial no Brasil. 5. ed. revista e atualizada. Rio de Janeiro: Forense, 2015.

AMARAL, Maria Lúcia. A Forma da república. Uma introdução ao estudo do direito constitucional, Coimbra Editora, 2005.

ANNONI, Danielle. Direitos humanos \& acesso à Justiça no direito internacional. Curitiba: Juruá, 2005.

BRASIL, Constituição dos Estados Unidos (1946). Disponível em:< https://www.planalto.gov.br/ccivil_03/Constituicao/Constituicao46.htm>. Acesso em: 14 nov. 2016. 
. Constituição da República Federativa do Brasil de 1988. Disponível em:<

http://www.planalto.gov.br/ccivil_03/constituicao/constituicaocompilado.htm>. Acesso em: 24 out. 2016.

CANOTILHO, J. J. Gomes; MOREIRA, Vital. Constituição da República Portuguesa anotada. V. I. 4. ed. Coimbra: Coimbra Editora, 2007.

CAPPELLETTI, Mauro; GARTH, Brian. Acesso à Justiça. Tradução e revisão Ellen Gracie Northfleet. Porto Alegre: Sérgio Antonio Fabris, 1988.

CARNEIRO, Paulo Cezar Pinheiro. Acesso à Justiça. Juizados especiais e ação civil pública. Rio de Janeiro: Forense, 1999.

CASTELLS, Manuel. A sociedade em rede. Tradução de Roneide Venancio Majer com a colaboração de Klauss Brandini Gerhardt. vol. 1. 8. ed. rev. ampliada. São Paulo: Paz e Terra. 2005 .

CICHOCKI NETO, José. Limitações ao acesso à justiça. 1. ed. 5. tiragem. Curitiba: Juruá, 1998.

CLEMENTINO, Edilberto Barbosa. Processo judicial eletrônico. O uso da via eletrônica na comunicação de atos e tramitação de documentos processuais sob o enfoque histórico e principiológico, em conformidade com a lei $\mathrm{n}^{\circ} 11.419$, de 19.12.2006. 2. reimpressão. Curitiba: Juruá, 2012.

CONTIJO, Danielly Cristina Araújo. O direito fundamental de acesso à Justiça, em especial, as ações previdenciárias sem prévio requerimento administrativo no contexto brasileiro. São Paulo: LTr, 2015.

DUDH. Declaração Universal dos Direitos Humanos. Adotada e proclamada pela Assembleia Geral das Nações Unidas (resolução 217 A III) em 10 de dezembro 1948. Disponível em: $<$ https://www.unicef.org/brazil/pt/resources_10133.htm>. Acesso em: 14 ago. 2018.

GALDINO, Flávio. A evolução das ideias de acesso à Justiça. p. 65- 66, In: Revista autônoma de processo. Curitiba: Juruá, n. 3, abr./jun. 2007.

GALLIEZ, Paulo. Princípios institucionais da defensoria pública. 4. ed. revista, ampliada e adaptada à LC 132/2009. Rio de Janeiro: Lumen Juris, 2010.

GIMENEZ, Charlise Paula Colet. O papel do terceiro mediador na política pública brasileira de tratamento de conflitos- Resolução ${ }^{\circ} 125$ de 29 de novembro de 2010 do Conselho Nacional de Justiça brasileiro- à luz da experiência do modelo do tribunal de múltiplas portas do distrito de Colúmbia, Estados Unidos da América. Tese doutoramento. UNISC: Santa Cruz do Sul, 2016. Disponível em: <

http://repositorio.unisc.br/jspui/bitstream/11624/1105/1/Charlise\%20Paula\%20Colet\%20Gimen ez\%20TESE.pdf.> Acesso em: 14 ago.2018.

Federal. Disponível em: <http://repositorio.ipea.gov.br/bitstream/11058/5279/1/Comunicados_n83_Custo_unit\%C3\%A 1rio.pdf.>. Acesso em: 14 ago.2018.

LÉVY, Pierre. O que é virtual. Tradução de Paulo Neves. São Paulo: Editora 34, 1996.

Revista Brasileira de História do Direito | e-ISSN: 2526-009X| Porto Alegre | v. 4 | n. 2 |

p. $01-16$ | Jul/Dez. 2018 
LUZ, Vladimir de Carvalho. A assessoria jurídica popular no Brasil. Rio de Janeiro: Lumen Juris, 2008.

MATTOS, Fernando Augusto Mansor de; CHAGAS, Gleison, José do Nascimento. Desafios para a inclusão digital. Perspectivas em Ciência da Computação. Vol. 13, n. 1, p. 67-94.

jan/abri. 2008. Disponível em: 〈http://www.scielo.br/pdf/pci/v13n1/v13n1a06.pdf>. Acesso em: 14 ago. 2018.

MINISTÉRIO DAS COMUNICAÇÕES. Disponível em:<

http://agenciabrasil.ebc.com.br/geral/noticia/2016-05/ministerio-lanca-programa-para-ampliaro-acesso-internet-em-alta-velocidade>. Acesso em: 14 ago. 2018.

MORAIS, José Luis Bolzan de. O Estado e suas crises. Porto Alegre: Livraria do Advogado, 2005.

OLIVEIRA, Daniela Olímpio de. Desjudicialização, acesso à Justiça e teoria geral do processo. 2. ed. revista e atualizada. Curitiba: Juruá, 2015.

OST, François. O tempo do direito. Tradução Maria Fernanda Oliveira. Lisboa: Instituto Piaget, 1999.

.Contar a lei: as fontes do imaginário jurídico. Tradutor Paulo Neves. Editora

UNISINOS: São Leopoldo, 2007.

REALE, Miguel. Liberdade e democracia. São Paulo: Saraiva, 1987.

SANTOS, Boaventura de Sousa. Pela mão de Alice: o social e o político na pós-modernidade.

São Paulo: Cortez, 1995.

Para uma revolução democrática da justiça. Coimbra: Almedina, 2014.

SEN, Amartya. A ideia de justiça. Tradução Denise Bottmann e Ricardo Doninelli Mendes. São Paulo: Companhia das Letras, 2011.

SILVEIRA, Sérgio Amadeu da. Exclusão Digital. A miséria na era da informação. São Paulo: Editora Fundação Perseu Abramo, 2001.

TAVARES, Rosilene Horta. Analfabetismo funcional versus aprendizagem qualificada: a importância da autonomia intelectual. In: 14 Congresso Anual da Associação Brasileira de Educação à Distância, 2008. Santos. Disponível em:

<http://www.abed.org.br/congresso2008/apr/TC041.ppt.> Acesso em: 17 ago. 2018. a

TORRES, Jasson Ayres. O acesso à Justiça e soluções alternativas. Porto Alegre: Livraria do Advogado, 2005.

WATANABE, Kazuo. Acesso à justiça e sociedade moderna. In: Participação e Processo, São Paulo, 1988. p. 128-131. 